\title{
SOLVING THE PROBLEM OF AIRCRAFT SAFETY DURING COMBAT SHOOTING BY AIR DEFENSE MEANS
}

\section{MARAT MEYERBEKOV, KUANDYK ZAKARIYA, KARASSAY KURMANSEITOV \& ADILBEK BEKMAGAMBETOV}

National University of Defense of the First President of the Republic of Kazakhstan - Elbasy, Nur-Sultan, Kazakhstan \begin{abstract}
The article raises the issue of aircraft safety during practical shooting by air defense calculations at targets. In order to ensure safety, information about the flight path of the target missile is required. To solve the problem of determining the trajectory data of the target rocket flight, it is proposed to use the radio-detonator of an anti-aircraft guided missile, converted into a missile target, in a new capacity - a source of radar information. This radar information is received by two receiving points located on the ground and separated from each other. Information from two receiving stations calculates the current projected range of the missile target using the triangulation method. The calculated projection range of the missile target is compared with the allowed range. If the flight of the missile target goes beyond the boundaries of the permitted sector, the "self-destruct" command is issued on Board the missile target. The principle of operation of the radio detonator allows for minimal changes in the design to use it in solving problems of aircraft safety during combat firing by air defense combat calculations. The use of a converted radio detonator, two receiving stations separated from each other and the calculation of the projection range by triangulation will ensure the safety of aircraft and people and objects on the ground is confirmed by the proposed technical solution and mathematical formulas.

KEYWORDS: Security, Radar, Anti- Aircraft Guided Missile, Target Missile, Radio Detonator
\end{abstract}

Received: May 28, 2020; Accepted: Jun 18, 2020; Published: Jun 30, 2020; Paper Id.: IJMPERDJUN2020268

\section{INTRODUCTION}

Ensuring the safety of aircraft that perform regular flights during exercises with live fire by air defense means is an urgent problem. This is proved by the tragedy of 2001, when a Tu-154 of the Sibir airlines crashed over the Black sea. It was on a flight from tel Aviv to Novosibirsk, with 66 passengers and 12 crew members on Board, all of whom were killed. The interstate aviation Committee concluded that the plane was shot down by an anti-aircraft guided missile launched from the S-200 complex, while Ukraine was conducting air defense exercises [1].

\section{PURPOSE OF RESEARCH}

Development of technical solutions for determining the trajectory data of the flight of a missile target, using the radio detonator of an anti-aircraft guided missile, converted into a missile target, in a new capacity as a source of radar information.

\section{MATERIALS AND METHODS}

The research material is a radio-detonator of an anti-aircraft guided missile and the development of a technical solution for its use in a missile target in another capacity. To achieve the research goal, statistical methods, system analysis and modeling were used. 


\section{RESULTS AND DISCUSSIONS}

In Soviet times, live-fire exercises of the air defense forces were conducted at ranges that had large areas that allowed for safe firing by air defense means. In addition, they were equipped with special telemetry equipment that allowed them to track the flight paths of targets and anti-aircraft guided missiles. Currently, there is no such equipment at the Saryshagan test site (Kazakhstan), and time requires the creation of technical means that can solve the problem of determining the trajectory data of the target rocket flight, in order to ensure the safety of ground objects, as well as to confirm the target's defeat, calculations of the air defense forces.

Air defense systems have anti-aircraft missile systems (SAMS) and systems that determine the current coordinates (sight) of the target and the missile, develop control commands for the missiles to guide them to the target. Target and missile sightings are based on the following principles: target-active radar with passive response; missile-active radar with active response (missile responder) [2].

Ground control station Sam irradiates the target. Simultaneously with the signals reflected from the target, the signals of the missile responder are received. Simultaneous reception of signals reflected from the target and the missile signals allows you to determine the position of the missile relative to the target at any time. Data on the position of the missile and the target are received by the ground station's counting and decision device, which generates control commands transmitted to the missile. The principle of operation of the pulse radio control and sighting is based on determining the position of the missile relative to the target at any time, followed by the development of a command to control the missile.

When using an anti-aircraft missile as a missile target, determining its coordinates according to the responder's data to control the performance of the missile target of the specified flight path is not advisable for reasons:

- The ground control station of the target rocket issues control commands directly to the target rocket to work out the specified flight path, i.e. perform performing tasks. System that performs performing the task, cannot effectively carry out the tasks of control. Therefore, separate ground control stations are needed in the system of measuring means of the polygon, especially if this is related to the safety of the target rocket application;

- Structurally, the Respondent's antennas are located in the tail section at the end of the target rocket, which will definitely make it difficult to use information from the Respondent to obtain trajectory data of the target flight at control ground stations, since ground control stations are located in other areas of the terrain;

- Re-equipment of the missile to receive information from the responder (transfer of the responder's antennas to the front of the rocket) or modification of the ground control station, in order to obtain reliable information about the flight of the target, for control ground stations, will lead to significant material costs.

To solve the problem of determining the trajectory data of the flight of a missile target, it is proposed to use the radio detonator of an anti-aircraft guided missile, converted into a missile target, in a new capacity as a source of radar information.

Radio controlled fuses included in the on-Board equipment surface to air missile and is designed to generate pulse triggering (initiation) at undermining the warhead anti-aircraft missiles when approaching a target at a time when the greatest defeat the purpose of the elements of combat units $[3,4$,$] .$ 
The radio fuse consists of an antenna system, a transmitter with a power supply, and a receiver. The antenna system is designed for radiating radio pulses in the direction of the target and receiving signals reflected from it [3, Fig. 1]. The directional Diagram of the antenna system of the radio fuse for transmission and reception has the form of a funnel with a changing angle depending on the duration of the command "K4" at the vertex $\varphi$. the Command "K4" is issued from the ground control point on Board the rocket in flight. The duration of the command depends on the relative speed of the missile's approach to the target [3, p.12-28]. The total radiation pattern of the radio fuse antenna system is shown in figure 1.

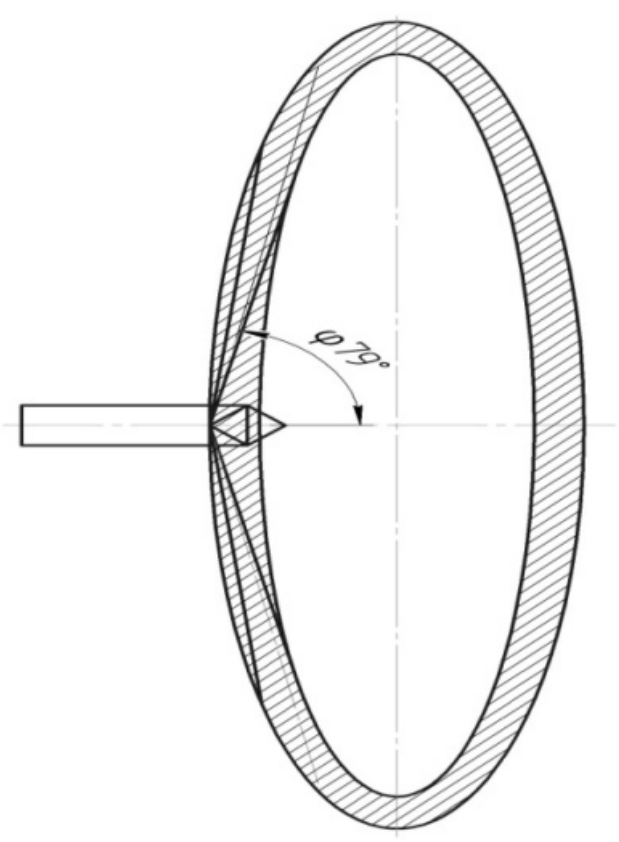

Figure 1: Total Radiation Pattern of the Antenna System.

The transmitter is designed to generate high-frequency pulses emitted by the transmitting antenna into space. It begins to work on the command "K3" (the command of cocking the radio fuse), which is issued from the ground control point on Board the rocket in flight [3, p. 11-35].

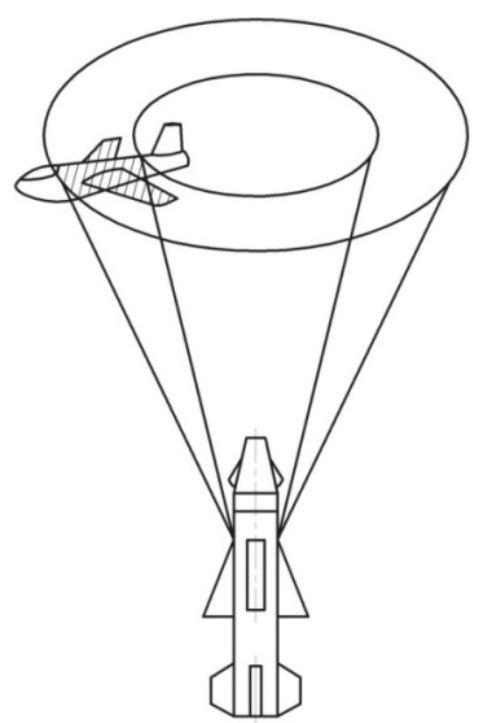

Figure 2: The Case of a Missile Meeting with a Target. 
The receiver receives and amplifies the signal reflected from the target, generates a trigger pulse and outputs it to the safety-actuating mechanism [4, Fig. 1]. The safety-actuating mechanism ensures the safety of the explosive device during operation, start and on the trajectory until the end of cocking and serves to issue a detonation pulse to the initiating charge of the warhead [3, p.70]. One of the possible cases of a missile meeting with a target is shown in figure 2.

The principle of operation of the pulse radio fuse is based on the use of the pulse method of active radar [3, p.712]. When the command "K3" is received, from the ground control point on Board the rocket in flight, the transmitter of the radio fuse is turned on. Through the transmitting antenna, energy is radiated to the surrounding space in the form of short high-frequency pulses. In case of contact with targets in the radiation pattern of the antenna system to the input of the receiver receives reflected from the target signals. The signals reflected from the target are processed in the receiver and generate a trigger signal, i.e. issues an impulse to detonate the warhead of the missile through the safety-actuating mechanism, to hit the target.

When converting an anti-aircraft missile into a missile target, the radio fuse is not used for its intended purpose, so it is advisable to use the radio fuse as a source of radar information. Figure 3 shows the solution to the problem of ensuring the safety of ground objects from a target rocket in flight, when using a radio fuse as a source of radar information to determine the trajectory data of the target rocket flight.

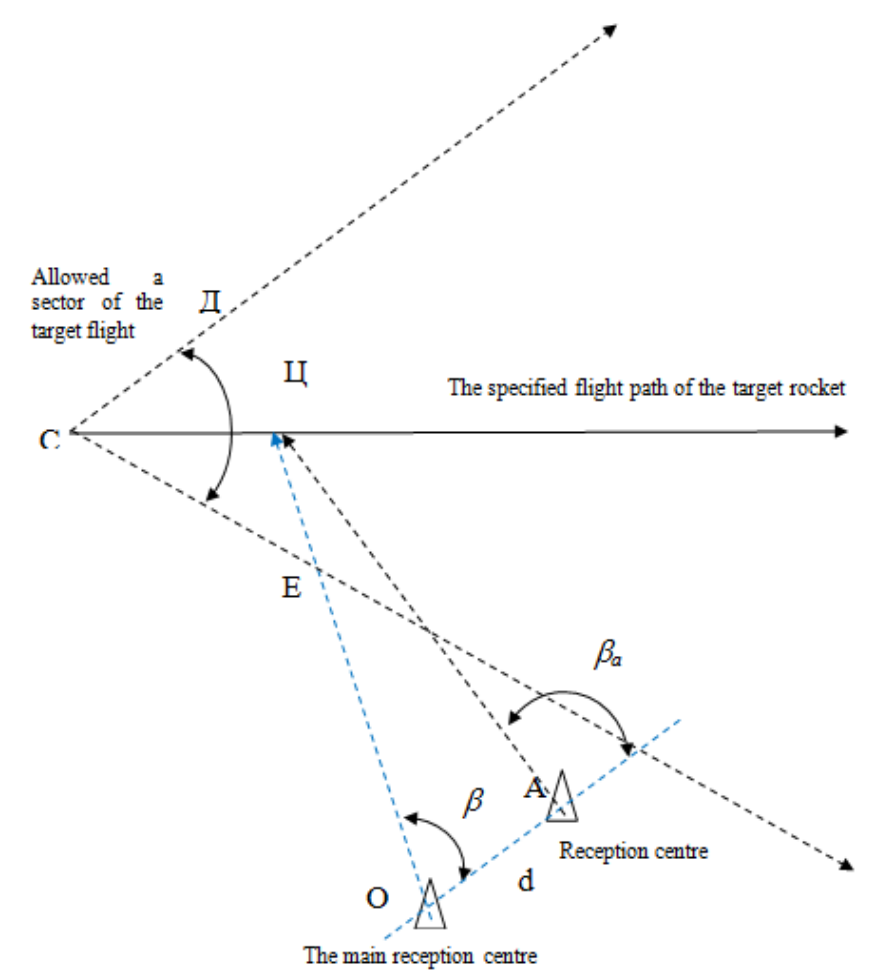

Figure 3: Ensuring the Safety of Ground Objects from a Missile Target in Flight, When using Radio Explosives as a Source of Radar Information.

The target is launched from the launch point of target C. the target is flown in the permitted flight sector. In flight, the bearing of the target is determined by two receiving stations, the main one at point $\mathrm{O}$, and the additional one at point $\mathrm{A}$. The distance to the target is calculated by solving the triangulation problem based on certain directions. The triangulation problem is solved by a logical device based on the main receiving center. In this case, the source of radar information is proposed to use the generated pulses of high-frequency energy of the radio fuse. 
Figure 4 shows the determination of the range by the angle-measuring method [5].

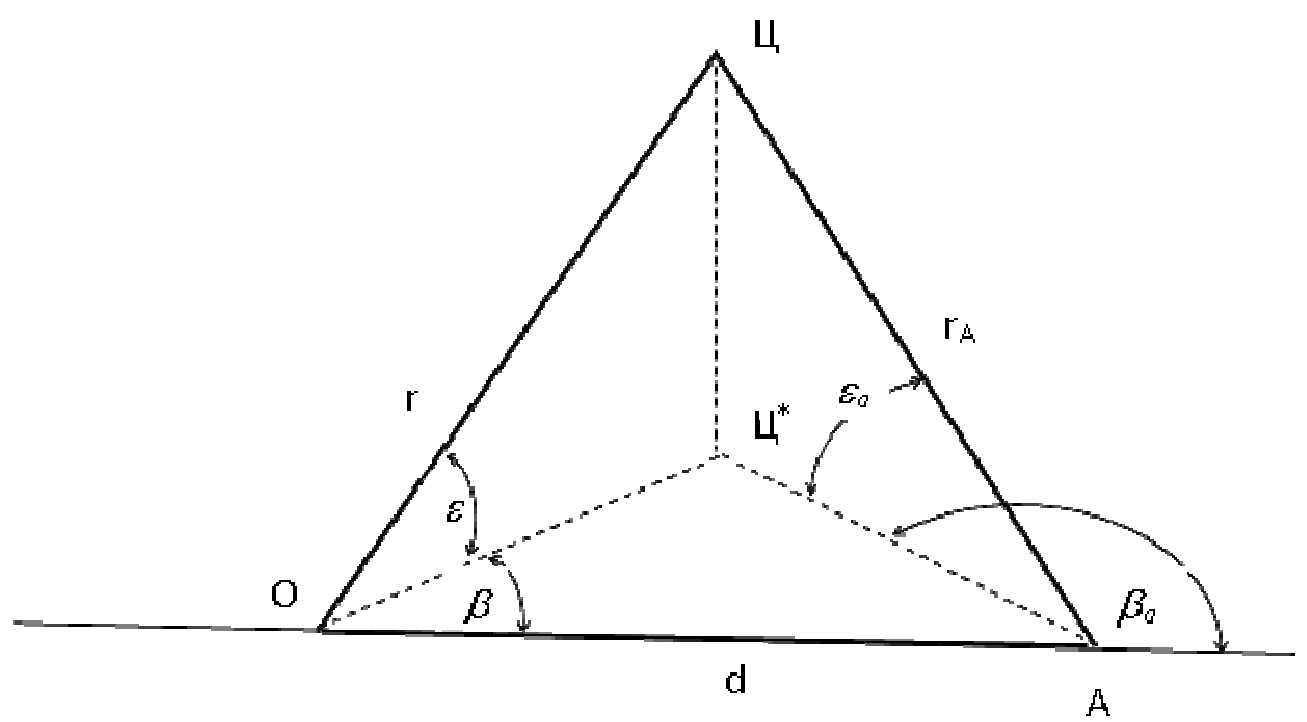

Figure 4: Determination of the Range by the Angle-Measuring Method.

One receiving point is located at point $\mathrm{O}$, and the second at point $\mathrm{A}$. It is sufficient to measure three angular coordinates: azimuth $\beta, \beta_{\mathrm{a}}$ and elevation $\varepsilon\left(\varepsilon_{\mathrm{A}}\right)$ or the elevation angles $\varepsilon, \varepsilon_{\mathrm{a}}$ and azimuth $\beta\left(\beta_{\mathrm{a}}\right)$.The expression connecting the target range with $\beta, \beta_{\mathrm{a}}, \varepsilon$ has the form [4, p. 146-147]:

$$
\gamma=d * \sin \beta \alpha /(\cos \mathrm{a} \sin (\beta \alpha-\beta))(2)
$$

Given that the distance from the air object to the receiving centers is sufficient projection, i.e. $\varepsilon=0(\cos 0=1)$. The formula will take the following form:

$$
r=d \sin \beta a /(\sin (\beta a-\beta))(3)
$$

The logic device calculates the current projected range to the missile target (O OC】^*) using formula 2 . The calculated current ranges are compared with the ranges to the boundaries of the permitted flight sector of the missile target (OE and OD).

If: $|\llbracket \mathrm{OC} \rrbracket \wedge *|<|\mathrm{OE}|$ or $|\llbracket \mathrm{OC} \rrbracket \wedge *|>|\mathrm{OD}|$, then a self-destruct command is issued on Board the missile target. This ensures the flight of the missile target, only in the permitted flight sector.

In addition, a change in the target's flight course, when an anti-aircraft guided missile is detonated in the area of the missile target, will be a confirmation of the defeat of the missile target by the calculations of the air defense forces.

Changing the flight of a missile target on the course is determined by the above method - calculating the range to the missile target by solving a triangulation problem.

The change in the flight of a missile target by height can not be determined by the above method, because the range from the air object to the receiving centers is used projection, which is a disadvantage.

Basic signs of defeat of target missile anti-aircraft guided missile: 
- Simultaneous disappearance of pulses of high frequency energy attack missile target after the detonation of the warhead anti-aircraft guided missile, in both reception centres.

- Change in the flight of the missile target on the course after the detonation of the anti-aircraft guided missile warhead, at both receiving centers.

When working in normal mode, the radio fuse is an active radar station with a passive response from the target. The maximum range of active radar for passive targets is determined by the basic radar equation[6]:

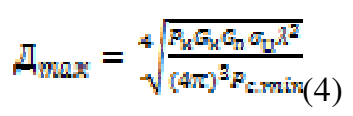

Where: $P_{-}$i-radiated energy of the transmitter;

G_i,G_p-gain coefficients of the transmitting and receiving RF antennas;

$\sigma_{-}$c-effective reflecting surface of the target;

$\lambda$-wavelength;

$P_{-}$(p. min) - the minimum sensitivity of the receiver

When the radio fuse is used for a new purpose, it will be a radar station with active radiation. Ground receiving stations, tuned to the frequency of the probing pulse of the radio transmitter, will receive signals from the maximum range, which is determined by the equation [7]:

$$
I_{\max }=\sqrt{\frac{P_{B} G_{k} G_{n} \lambda^{2}}{(4 \pi)^{2} F_{c \min }}(5)}
$$

Comparison of equations (4) and (5) shows that the actions of systems with active radiation under equal conditions are significantly longer than the range of active radar for passive targets.

When using the radio fuse for a new purpose (radar station with active radiation), under equal conditions, the receiving stations will receive signals from the radio fuse with a longer range than the standard application (active radar station with a passive response from the target).

If the detection range of the receiving stations of the sounding signals of the radio fuse needs to be increased, this will be possible by improving the directional coefficient of the receiving antenna and the sensitivity of the receiving device of ground control stations.

\section{CONCLUSIONS}

The solution of the technical problem of determining the trajectory data of the flight of a missile target is implemented by the method of triangulation, in order to ensure the safety of people and objects during combat firing by air defense means.

\section{ACKNOWLEDGEMENTS}

The authors are very grateful to the Ministry of education and Science of the Republic of Kazakhstan for providing financial assistance in conducting this research. 


\section{REFERENCES}

1. Ahmad, Z., and B.J. Abdul Aleem (2009). Erosion-Corrosion Behavior of Plasma Sprayed Nanostructured Titanium Dioxide Coating in Sodium Chloride-Polystyrene Slurry. Corrosion, 65, 9, 611 - 623.

2. Bhadra, S., Singha, N. K., Lee, J. H., and D. Khastgir (2009). Progress in preparation, processing and applications of polyaniline. Prog. Polym. Sci., 34, 783-810.

3. Bhadra, S., Singha, N. K., and D. Khastgir (2011). Polyaniline based anticorrosive and anti-molding coating. Journal of Chemical Engineering and Materials Science, 2(1), 1-11.

4. Bibber, J. W. (2009). Chromium-free conversion coatings for zinc and its alloys. Journal of Applied Surface Finishing, 2 (4), 273-275.

5. Bousser E., Benkahoul M., Martinu L., and Klemberg-Sapieha J.E. (2008). Effect of Mi-crostructure on the erosion resistance of Cr-Si-N coatings. Surface \& Coatings Technology, 203, 776- 780.

6. Belotserkovsky M., Nurakov S. (2019). Methods of coating deposition in mechanical engineering: Textbook. - Almaty: SSK, 176.

7. Creus, J., Brezault, F., Rebere, C., and M. Gadouleau (2006). Synthesis and characteri-sation of thin cerium oxide coatings elaborated by cathodic electrolytic deposition on steel substrate, Surf. Coat. Technol. 200, 14-15.

8. Chaturvedi, Mr Shubhankar. "Indigenization of Air Powered Fuzes for Submunition Grenades." (2018).

9. Deen, K. M., Ahmad, R., and I.H. Khan (2009). Corrosion Protection Evaluation of Mild Steel Painted Surface by Electrochemical Impedance Spectroscopy. Journal of Quality and Technology Management, 5, 1, 6.

10. Durodola, B. M., Olugbuyiro, J. A. O., Moshood, S. A., Fayomi, O. S. and A.P.I. Po-poola (2011). Study of Influence of Zinc Plated Mild Steel Deterioration in Seawater Environment. Int. J. Electrochem. Sci., 6, 5605 - 5616.

11. Davydov V. M., Zuev V. V., Ponochevny P. N. (2013). Analysis of international practice of profile and three-dimensional surface roughness assessment. Electronic scientific publication Scientific notes of the Pacific state University, 4 (4), 1061 1074.

12. Fayomi O. S. I. and A.P.I Popoola (2012). An Investigation of the Properties of Zn Coated Mild Steel, Int. J. Electrochem. Sci., 7, $6555-6570$.

13. Gasem, Z.M. (2013). ME 472: Corrosion engineering 1, ocw.kfupm.edu.sa/ocw.courses/users062/ME4720102/LectureNotes/impact of Corrosion.pdf, accessed on 26/01/2013.

14. Ganesh, M. "Design of Airship for Aerial Surveillance and Communication Using Knowledge Based Engineering." International Journal of Mechanical and Production Engineering Research and Development (IJMPERD) 8.1 (2018): 17-26.

15. Guosheng, H. GuDaming, g., Li Xiangbo, L., and X. Lukuo (2013). Corrosion Behavior of Oxyacetylene Flame Sprayed Zn-Ni Composites Coating with Spray-dried Agglomerating Powders in Natural Seawater, Int. J. Electrochem. Sci., 82905 - 2917.

16. Hammer, P., F. C. dos Santos, B. M. Cerrutti, S. H. Pulcinelli and C. V. Santilli (2012). Corrosion Resistant Coatings Based on Organic-Inorganic Hybrids Reinforced 264 Developments in Corrosion Protection by Carbon Nanotubes, Recent Researches in Corrosion Evaluation and Protection, Prof. Reza ShojaRazavi (Ed.), ISBN: 978-953-307-920-2.

17. Hara, M., Ichino, R., Okido, M., and N. Wadab (2003). AlN formation and enhance-ment of high-temperature oxidation resistance by plasma-based ion implantation, Surf. Coat. Technol. 169-170, 359-362. 
18. Hunag, Y. and J. Chen (2012). The Development of an Anti-corrosion Wrapping Tape and its Corrosion Protection Effect Evaluation on Mild Steel in Marine Splash Zone, Int. J. Electrochem. Sci., 7, 7121 - 7127.

19. Ige, O.O., Shittu, M.D., Oluwasegun, K.M., Olorunniwo, O.E. and Umoru, L.E. (2012). Eco-friendly Inhibitors for Erosioncorrosion Mitigation of API-X65 Steel in CO2 En-vironment, Ife Journal of Technology, 21 (2), 43 - 48.

20. Iroh, J. O., Zhu, Y., Shah, K., Levine, K., Rajagopalan, R., Uyar, T., Donley, M., Mantz, R., Johnson, J., Voevolin, N. N., Balbyshev, V. N., and A. N. Khramov (2003). Electro-chemical synthesis: A novel technique for processing multi-functional coatings, Prog. Org. Coat., 47: 365-375

21. Kadhim, Ibtihaj Ahmed. "The use of the nuclear detector effect (CR-39) in determining the concentration of radon in samples of the Nasiriya City soil, South of Iraq,"." INT. J. Res. Applied, Nat. Soc. Sci 2.11 (2014): 103-110..

22. Katz, Yaron. "Social Media Is Powerful, but Can It Change Policies of Institutionalized Organizations Such as the Israeli Army?." International Journal of Humanities and Social Sciences (IJHSS) 6.6 (2017): 29-34.

23. Khaled M. and E. Hashem (2011). Strengthening of Anticorrosion Passivity by Newly Developed Multi-silicon Coatings, Journal of Chemical Engineering and Materials Science, 2(1), 1-11.

24. Krishnamurthy, A., Gadhamshetty, V., Mukherjee, R., Chen, Z., Ren, W., Cheng, HM, and N. Koratkar (2013). Passivation of microbial corrosion using a graphene coating, Carbon, 56, 45-59.

25. Lamaka, S.V., Zheludkevich, M.L., Yasakau, K.A., Serra, R., Poznyak, S.K., and M.G.S. Ferreira (2007). Nanoporoustitania interlayer as reservoir of corrosion inhibitors for coatings with self-healing ability, Prog. Org. Coat., 58, 127 - 135.

26. Lunder, O., Simensen, $C$., Yu, Y., and K. Nisancioglu (2004). Formation and charac-terisation of Ti-Zr based conversion layers on AA6060 aluminium, Surf. Coat. Tech-nol. 184, 2-3, 278- 290.

27. Nurakov S., Belotserkovsky M.A., Togusov A.K., Tulebekova A., Belikov K.L. (2018). Modern spraying technologies of wearresistant and protective coatings. Nur-Sultan: National Defense University named after the First President of the Republic of Kazakhstan - Leader of the Nation, 125.

28. Nurakov S., Belotserkovsky M., Merzadinova G., Aitlessov K. (2019). Modification of sprayed with supersonic coatings by microplasma oxidation. Procedia Computer Science, 149, 319-323.

29. Nurakov S., Atlasov K. (2017). the Relationship of roughness and functional properties of surfaces. Bulletin of the Gumilyov ENU, 4, 137-141.

30. Nurakov S., Belotserkovsky M., Suleimenov T., Aitlessov K. (2019). Application of chemical-thermal treatment for hardening of sprayed with supersonic coatings. Procedia Computer Science 149, 360-364.

31. Polyansky S. N., Butakov S. V., Alexandrov V. A., Lazareva L. Yu. Surface preparation for applying anticorrosive coatings on metal structures and details of mechanisms made of carbon steels. Modern problems of science and education, $2014,4$.

32. Suslov A. G., Bezylazny V. F., Panfilov Yu. V. (2008). Engineering of surfaces of details. - Moscow: Mashinostroenie, 316.

33. Zhaoxin Rena, Bing Wangb, GaomingXiangb, Dan Zhaoc, LongxiZhenga (2018). Supersonic spray combustion subject to scramjets: Progress and challenges. Progress in Aerospace Sciences, 21, 20-23. www.elsevier.com/locate/paerosci

34. Stony Brook (2020). Progress in Supersonic Spray Combustion Modeling. AIAA Life Member and Associate Fellow.

35. Stony Brook (2019). Evaluating the Correlations for Supersonic Spray Combustion. AIAA SciTech Forum, 7-11 January, San Diego, California. 
36. Stony Brook (2018). Dynamics of Supersonic Spray Combustion. AIAA Propulsion and Energy Forum, July 9-11, Cincinnati, Ohio.

37. Tokyo Scinutsu Co. Ltd (2006). Application guide manual for surfcom series surface roughness \& waviness parameters. Tokyo, 96. 

